\title{
El control de los contenidos televisivos en las autoridades reguladoras y los consejos audiovisuales
}

\author{
José Ignacio Aguaded Gómez, Ángel Luis Vera Aranda \\ (Universidad de Huelva) \\ Recibido: 01/09/08 \\ Aprobado: 08/10/08
}

RESUMEN: En este trabajo se realiza una síntesis de los orígenes de las autoridades de regulación audiovisual, analizando sus funciones reguladoras y las competencias para el control de los contenidos. Asimismo, se reflejan las actuaciones de los consejos audiovisuales en el análisis de los contenidos y la problemática de este análisis con sus instrumentos para el control: sanciones, recomendaciones, instrucciones, para finalizar concluyendo que las sociedades libres e independientes necesitan de su existencia como vía tanto de canalización de sus demandas contra los abusos en los medios, como de elementos de protección ante los colectivos más desprotegidos que en su seno albergan.

Palabras clave: Supervisión audiovisual - autoridades reguladoras - contenidos espectadores - censura - libertad de expresión

\section{The control of television content by the regulatory authorities and audiovisual councils}

SUMMARY: This work is a synthesis of the origins of these audiovisual regulatory authorities, analysing their regulatory functions and responsibilities regarding control of content. It also reflects on the actions taken by Audiovisual Control Boards as a result of their analysis of content and the problems arising from these analyses, along with their instruments of control: sanctions, recommendations, instructions...to conclude that free and independent societies need these boards to exist as a means of channelling their demands against the abuses of the media, and as elements that protect the most vulnerable sectors of those societies.

Key words: Audiovisual supervision - regulatory authorities - contents - viewers censorship - freedom of expression 


\section{Los orígenes de las autoridades de regulación}

T a necesidad de regular los conte$\amalg$ nidos que se emiten por los medios audiovisuales surge casi paralelamente a la aparición y divulgación de los medios de comunicación. La popularización de la radiodifusión a partir de la década de 1920, y de la televisión, a partir de la década de 1930, implicaron, en forma casi inmediata, la creación de organismos que controlaran, en la medida de lo posible, los contenidos que se emitían por esos medios de comunicación.

En este sentido, ya en 1934 se creó en Estados Unidos la Comisión Federal de Comunicaciones (FCC, por sus siglas en inglés), con el objetivo, entre otros, de supervisar las emisiones audiovisuales, aunque en la actualidad sus competencias son mucho más extensas de lo que fueron en un principio, hasta convertirse en un organismo con una amplia autoridad en materia de medios de comunicación.

Desde ese momento, los países en los que los medios audiovisuales iban alcanzando cada vez un mayor desarrollo, se sumaron paulatinamente al ejemplo norteamericano y fueron creando diferentes organismos de supervisión y de control sobre los contenidos que emitían las cadenas televisivas y radiofónicas.

Estos organismos han ido evolucionando con el tiempo, adquiriendo, como en el caso norteamericano, cada vez mayor importancia y abarcando progresivamente un mayor número de funciones. Aunque en algunos casos sus orígenes pueden rastrearse incluso desde antes de mediados del siglo $\mathrm{XX}$, los actuales consejos audiovisuales de los principales países europeos datan de fechas relativamente recientes, tras experimentar diferentes transformaciones en sus funciones y objetivos.

El CSA francés (del que directa o indirectamente se han basado los consejos existentes en nuestro país); el ALM alemán (que sigue una estructura parecida a la española, con un peso bastante fuerte de los diferentes Landers o regiones en el control de los contenidos); el Ofcom británico, más reciente que los anteriores, aunque la BBC fuera la primera cadena en emitir contenidos televisivos allá por la década de 1920; la Agcom italiana, etcétera, tienen sus orígenes en las últimas décadas del siglo XX, creándose básicamente a partir de mediados de la década de 1980.

En España, las autoridades reguladoras se han incorporado con bastante retraso a la legislación europea en materia de control audiovisual. En la actualidad, España es el único de los grandes países europeos y uno de los escasos países del mundo desarrollado que no cuenta con una autoridad nacional que regule los contenidos audiovisuales, donde la Secretaria de Estado para las Telecomunicaciones y la Sociedad de la Información 
(SETSI) es el organismo que cumple las funciones que debería tener un Consejo Audiovisual Nacional.

Por el contrario, y en consonancia con la situación de descentralización administrativa que se experimenta en nuestro país desde 1978, han sido las diferentes comunidades autónomas las que han dado los primeros pasos para dotarse de organismos de regulación y control de los contenidos que emiten la televisiones o la radio que operan en su territorio.

En este sentido, fue Cataluña la comunidad pionera en disponer de un Consejo Audiovisual, el CAC. En 1995 se dieron los primeros pasos, dos años después la autoridad catalana ya era operativa, aunque su creación definitiva tuvo lugar en el 2000.

Solo existen en la actualidad otros dos consejos audiovisuales en España, el de Navarra, creado el 2001, y el de Andalucía, que inició su andadura el 2004, aunque no se constituyó realmente hasta el año siguiente. La comunidad de Madrid es un caso paradigmático en este sentido. En ella se creó, el 2001, un embrión de consejo audiovisual, pero los avatares políticos propiciaron su disolución y falta de operatividad pocos años después.

Otras comunidades -como Galicia o Valencia- preparan futuros consejos audiovisuales, pero de momento no se han dado los pasos definitivos para su creación.

\section{Funciones de las autoridades reguladoras}

Frecuentemente se ha señalado que uno de los objetivos fundamentales de los consejos audiovisuales es el de servir como garantía de libertades. Sin embargo, en opinión de aquellos que juzgan ineficaz o contraproducente su existencia, se han planteado que su creación obedece más a los deseos de censurar la información o los contenidos televisivos que a salvaguardar los derechos de los espectadores o a garantizar la libertad y la independencia de los medios de comunicación.

Este es un debate abierto, en el que las posturas encontradas defienden, a veces de forma desmedida, planteamientos contrapuestos $y$, en ocasiones, hasta malintencionados.

Ciertamente, las autoridades reguladoras ejercen una función de control indiscutible sobre aquellos contenidos que se emiten por radio y televisión, lo cual implica necesariamente el poder decidir qué es pertinente en las emisiones y qué no lo es de acuerdo con la normativa o con los códigos éticos y deontológicos con los que las sociedades y los medios de comunicación se han dotado.

Pero independientemente de esa cuestión, a nadie se le escapa la necesidad de controlar, de la forma más racional posible, la existencia de un enorme mercado de las comunicaciones en el cual la regulación de los 
contenidos que se emiten aparece como un hecho fundamental en aras de una protección de determinados grupos sociales minoritarios o necesitados de protección, cuando no incluso de ideologías políticas o de otro carácter (sindicatos, asociaciones de diversos tipos, etcétera).

La canalización de las quejas de los propios telespectadores o radioyentes es otra de las funciones básicas que estos organismos tienen encomendadas. En este sentido, los consejos audiovisuales actúan como entidades que facilitan al público la resolución de sus demandas contra los medios de comunicación que incumplen, desde su punto de vista, con los criterios que las leyes o la ética aconsejan.

Estos serían, básicamente, los dos objetivos principales que las autoridades reguladoras deben cumplir ante la audiencia. Pero hay otros también muy importantes, aunque no todos los organismos de control las hayan asumido en la misma medida. La supervisión del espacio radioeléctrico, la concesión de emisoras o de licencias, la información sobre los grupos económicos, o del tipo que sean, que hay detrás del negocio comunicativo, etcétera, son otras funciones que determinadas autoridades de control han asumido; aunque no en todos los casos, como el español, ha sucedido así.

\section{Las competencias de las autoridades reguladoras para el control de los contenidos}

Hace relativamente poco tiempo, estalló una agria polémica en torno a una decisión que había tomado el CAC, la autoridad reguladora de Cataluña. El motivo de la polémica era el supuesto intento de cerrar una emisora de radio debido a los contenidos que emitía. Este debate sirvió, entre otras cosas, para demostrar que los organismos reguladores están todavía en muchos lugares bastante lejos de contar con la capacidad para ejercer un verdadero control sobre los contenidos que se emiten. En efecto, los consejos audiovisuales poseen capacidad de sancionar y, más frecuentemente, de recomendar determinadas actuaciones, pero se encuentran bastante limitados en la toma de decisiones importantes como la que nos ocupa.

Solo en algunos casos, como en aquellos en los que estas autoridades han asumido un verdadero y completo control de todos los ámbitos del espacio audiovisual, como ocurre en los organismos de mayor tradición y en países en los que existe una importante "cultura sobre los medios", es posible utilizar este tipo de recursos en los casos de incumplimientos más extremos.

Lo más frecuente es que los consejos audiovisuales se queden en organismos capaces de aconsejar, suge- 
rir o recomendar que se actúe en un sentido o en otro por parte de los operadores, siempre intentando que se aplique la normativa vigente o los códigos deontológicos que se han creado para cumplir determinados criterios a la hora de ofrecer la información y los contenidos al público.

En determinadas ocasiones, cuando los incumplimientos detectados alcanzan una acusada gravedad, los consejos audiovisuales pueden llegar a emitir decisiones en las que insten a los operadores a cumplir las directrices que de ellos emanan. Incluso, en los casos más extremos, se puede llegar a proponer sanciones económicas debido a que las faltas cometidas alcanzan ya un grado de infracción muy elevado, pero esto es poco frecuente.

En el caso de España la situación se complica aún más al no existir un organismo regulador que tenga como ámbito el espacio nacional en su totalidad. Diferentes problemas de tipo político han impedido que esto suceda, y en el horizonte a corto plazo no parece que esta situación se vaya a solucionar como mínimo antes del 2009.

Para cubrir el vacío que deja esta ausencia de organismo regulador centralizado, el Estado ha creado una serie de organismos complementarios que realicen esta labor como la SETSI o la Comisión del Mercado de las Telecomunicaciones (CMT), con funciones muy distintas y no siempre complementarias. No en todos los casos se ha tratado de una iniciativa estatal, incluso las propias empresas privadas han auspiciado el surgimiento de organizaciones como autocontrol, una especie de "censura previa" que actúa sobre los anuncios que infrijan alguna de las normativas existentes en el sector, y otros como la Agencia de Calidad de Internet (The Internet Quality Agency, IQUA), para intentar poner un poco de orden en un medio tan conflictivo y poco "controlable" como es la red de internet.

\section{Las actuaciones de los consejos audiovisuales}

Por lo general, los organismos de regulación suelen tener dos formas de actuación sobre los contenidos audiovisuales. Por una parte se encargan de recibir las quejas y reclamaciones que la audiencia presenta cuando algún particular o colectivo entiende que se está incumpliendo alguna ley o norma. Es lo que genéricamente se denomina Oficina de Defensa de la Audiencia. Por otra parte, existen los llamados Servicios de Análisis de Contenidos que, como su nombre lo indica, analizan todos aquellos contenidos que son susceptibles de infringir también algún aspecto regulado por las leyes o códigos, con la salvedad de que en este caso la mayor parte de la información que manejan proviene no de denunciantes externos sino de sus propios recursos que detectan aque- 
llos programas o anuncios publicitarios que contravienen las normas y las leyes existentes.

Las oficinas de defensa de la audiencia se encargan de canalizar todas las quejas que los ciudadanos y las ciudadanas plantean ante los organismos de control. Como antes apuntábamos, no solo se trata de reclamaciones con carácter particular, sino que también muchos colectivos (ayuntamientos, sindicatos, partidos políticos, etcétera) presentan denuncias contra determinados medios por opinar que no se cumplen en ellos los criterios democráticos que fijan las leyes, el pluralismo político o social, o simplemente por estar descontentos ante el trato que reciben en algunos de esos medios.

En realidad, la dificultad de controlar a los operadores de tipo local es uno de los principales motivos por los que en muchas localidades pequeñas, los partidos o colectivos minoritarios sienten que se vulneran sus derechos y recurren a este tipo de organismos para conseguir una solución a su problemática.

En los operadores que emiten en ámbitos más extensos, esta problemática es menor, pero cuando aparecen las denuncias suelen poseer un carácter mucho más general e importante que en los pequeños municipios en los que el pluralismo político, por poner solo un ejemplo, es algo que difícilmente se cumple en los medios de comunicación públicos, generalmente al servicio del Partido o la opción política que detenta el poder.

Las ODA, como abreviadamente se las conoce, cumplen una labor abierta a toda la ciudadanía, a modo de una especie de Oficina del Defensor del Pueblo, solo que en este caso específicamente dirigida al control de los medios de comunicación y a defender a la audiencia de lo que una parte de esta puede considerar como un abuso o un exceso.

El caso de los servicios de análisis de contenidos es complementario al anterior, aunque su complejidad es mucho mayor. A veces se ha comparado a estos con una especie de policía que vigila para que los operadores no cometan ilegalidades y respeten la normativa. El problema es que la red de emisoras es tan amplia y se encuentra en continuo crecimiento (solo en Andalucía habría unas 400 emisoras de televisión a finales del 2007) que todo intento por abarcar el control de tan amplio espectro choca inevitablemente con la necesidad de tener recursos muy amplios y una avanzada tecnología que permita supervisar a tanta emisión de programación como se lanza a través de la televisión.

Por eso, una de las labores más importantes que estos servicios tienen encargadas es la del seguimiento de los contenidos televisivos. Este seguimiento, en comunidades con una gran oferta televisiva como es la andaluza, ha de ser forzosamente aleatorio e in- 
completo y, consecuentemente, solo puede detectarse un porcentaje relativamente bajo de las múltiples infracciones que con toda seguridad se cometen diariamente. Siguiendo con el ejemplo anterior, se podría decir que es como el control de las infracciones de tráfico, de las que solo una pequeña parte, aquellas en las que puede intervenir o que descubren los sistemas de control, son sancionadas quedando buena parte de las ilegalidades sin su correspondiente amonestación.

El método de trabajo es a grandes rasgos el siguiente: la propia autoridad reguladora, si posee los medios, o bien la empresa o empresas contratadas para realizar este trabajo, detectan mediante el visionado de las programaciones los incumplimientos que en ellas se producen. Inmediatamente que se detecta la alerta se procede a la labor técnica del análisis del contenido emitido, para esto no solo cuentan con los técnicos que realizan su labor en el área, sino que también se utilizan los servicios jurídicos para la emisión del correspondiente informe. Una vez puesta la infracción y el informe en conocimiento de la autoridad competente, se reúne el pleno de los miembros del consejo para decidir la actitud que se va a tomar para la solución del problema.

A partir de la decisión que en dicho pleno se tome se procede a comunicársela a los operadores para que estos retiren el programa o la pu- blicidad objeto de la denuncia $y$, en caso de no hacerlo, la decisión se derivaría a la vía judicial, pero esto es algo que no suele suceder casi nunca.

\section{El análisis de los contenidos}

Tanto la Oficina de Defensa de la Audiencia como el Servicio de Análisis de Contenido suelen estar agrupados en una entidad de rango mayor: el Área de Contenidos. Esto es así porque aunque las vías a través de las cuales se recibe la información son distintas, el proceso de trabajo que se sigue, es decir, el análisis, tanto en un caso como en otro, es muy parecido.

Sin duda, una de las labores más complejas y de mayor trascendencia que llevan a cabo las autoridades de regulación es la del análisis de los contenidos que se emiten por los medios audiovisuales.

En principio, son varios los medios susceptibles de ser analizados: internet, radio, televisión..., sin embargo, en la mayoría de casos, es este último el que más infracciones y alertas presenta a la mayor parte de la audiencia. El motivo es evidente, la televisión es -con una gran diferencia- el más importante en cuanto a consumo en general de los tres medios citados, de ahí que centralice la mayor parte de las actuaciones de los organismos de control. La radio ocupa el segundo lugar, bastante alejado de las emisiones televisivas. En cuanto a internet, desde hace mucho tiempo se dice 
que es el futuro, y en efecto esta frase cobra todo su valor cuando se analiza en el ámbito de los organismos reguladores. Ni la normativa ni las posibilidades reales existentes permiten un control medianamente efectivo de algo tan complejo y extenso como es la red de internet. Tendrá que desarrollarse aún mucho más la legislación y la tecnología, para que desde los consejos audiovisuales se pueda poner freno a la cantidad de contenidos ilegales y en muchos casos hasta peligrosos (sin duda mucho más que en los otros dos medios juntos) que se hacen públicos a través de la red.

Como se apuntó, para llevar a cabo el análisis de los contenidos los servicios técnicos que desempeñan esta tarea han de basarse principalmente en tres pilares: la legislación existente, los códigos deontológicos que son aceptados por la mayor parte de los operadores y publicistas y, en un nivel de menor importancia, la bibliografía y documentación publicada sobre este tipo de actividades.

A pesar de que los medios de comunicación audiovisual llevan ya emitiendo desde hace prácticamente un siglo, la legislación existente para el control de los contenidos que se emiten sigue siendo escasa y poco precisa. Muchas voces se han alzado en la sociedad pidiendo un mayor control y la imposición de limitaciones legales que impidan la emisión de cualquier tipo de contenido; pese a ello, la normativa existente no es espe- cialmente amplia y siguen habiendo bastantes lagunas sin cubrir. $\mathrm{Y}$ es obvio que de este hecho se aprovechan en muchos casos un gran número de operadores que emiten con un gran descontrol los programas que, entienden, les proporcionan mayor audiencia y por lo tanto mayores ganancias. La emisión de contenidos de carácter erótico e incluso pornográfico en horario infantil, la abusiva y en ocasiones hasta fraudulenta publicidad mediante SMS y otros tantos ejemplos por el estilo, son una prueba de esta situación.

En la actualidad, la legislación más importante existente al respecto es la Ley 25/1994 denominada genéricamente de la "televisión sin fronteras", pero aunque en ella aparecen unos criterios claros, la complejidad del fenómeno impide que muchas cuestiones (tratamiento de género, discriminación en sus diferentes formas, etcétera) queden sin cubrir. Otras leyes sirven para complementar la mencionada anteriormente, pero se echa en falta un corpus mucho más completo y sistemático que permita abordar con eficacia la complejidad del mundo audiovisual y de sus emisiones.

Los códigos deontológicos surgen como respuesta "desde dentro" para poner un cierto control o límite a las emisiones y sus contenidos. Periodistas y publicistas han creado sus propios códigos con el loable afán de que sean compartidos y respetados 
por todas las personas, organismos y empresas que forman parte del sector, pero a pesar de los esfuerzos realizados en esta materia, aún queda mucho por hacer en este sentido para obligar a que cierta parte del espectro antes citado acepte plenamente lo aprobado por su colectivo.

Finalmente, existe, como antes también citamos, una abundante bibliografía que ha abordado esta problemática desde diferentes puntos de vista: técnicos, jurídicos, pedagógicos, didácticos, etcétera. Aunque siempre las reflexiones teóricas son un buen apoyo para poner en práctica las medidas correctoras precisas, se observa que la mayor parte de estas obras poseen un fuerte contenido teórico que aborda el problema desde una perspectiva muy científica, pero poco práctica y operativa a la hora de atajar los incumplimientos y las infracciones.

Queda, por tanto, una amplia labor por hacer, ya no solo en el sentido real del control de los contenidos, sino en primer lugar de sistematizar las bases sobre las que estos han de apoyarse; también queda la labor de dar un sentido práctico y mucho más completo a la difícil tarea que se aborda.

\section{La problemática del análisis}

La variedad de los contenidos televisivos que se emiten es tal, que es preciso que las autoridades reguladoras se centren solo en aquellos aspectos que, o bien suelen prestarse a frecuentes incumplimientos que contradicen las normas y las leyes, o tienen una particular importancia dentro de la labor que, como garantes de la libertad y de la independencia de los medios, tienen los propios consejos audiovisuales.

Esta temática se ciñe por tanto a una serie de aspectos como: la defensa del pluralismo político y social; la protección de los menores: la infancia y la juventud en franjas horarias determinadas (de 6 a.m. a 10 p.m. y con un horario de protección reforzada para los menores de 13 años de 8 a.m. a 9 a.m. y de 5 p.m. a 8 p.m., además de los festivos $y$ fines de semana de 9 a.m. a 12 m.); la defensa de la igualdad de género; la cultura, la lengua o el habla propia del territorio sobre el que tienen competencias; la contraprogramación; el mundo de los inmigrantes o de otras minorías (gitanos y otros colectivos étnicos, etcétera); los derechos de las personas con discapacidad física o psíquica; los bloques de publicidad abusiva en cuanto a su duración (más de doce minutos por hora); el cumplimiento de las cuotas de obras europeas (en su caso); la falta de calidad televisiva: la denominada "telebasura"; las imágenes en las que aparece violencia gratuita; la señalización (cortinillas, programas recomendados por edades); la publicidad, etcétera.

El estudio de cada uno de estos ámbitos llevaría este trabajo a una 
extensión y una complejidad que está fuera de lugar. Es conveniente, por tanto, centrarse en uno de ellos para que sirva, siquiera a grandes rasgos, como referente de la labor que se desarrolla en este sentido.

Escojamos, por ejemplo, el caso de la publicidad. La variedad de tipos de publicidad susceptibles de ser analizados es muy amplia. Su catalogación es precisa para determinar qué clase de normativa o de código vulnera, ya que en cierta medida, la actuación de un consejo regulador estará en función de la importancia de esa infracción. Un listado que no pretende ser exhaustivo nos presenta diferentes tipos de publicidad: ilícita, prohibida, fraudulenta, engañosa, discriminatoria, subliminal, encubierta, virtual, abusiva, indirecta, desleal, etcétera. Cada uno de ellos posee una definición clara y precisa a la hora de ser abordado y unas pautas de tratamiento distintas en cuanto a su análisis se refiere.

Pero no solo es la publicidad clásica o tradicional la que es susceptible de ser analizada, sino también las nuevas formas de propaganda. Las denominadas telepromoción, autopromoción, telerreportajes, televenta, patrocinio televisivo, contraprogramación, publirreportajes... son otras facetas que muestran la complejidad de este mundo y la problemática que presenta el análisis de sus contenidos.

El mundo publicitario se presta a numerosos abusos con el objetivo claro de incentivar las ventas de un determinado producto, por eso es preciso tener un particular celo en el control de sus contenidos, ya que la imaginación de los publicistas en su afán por seducir a los potenciales consumidores se presta a toda clase de excesos y de abusos en general, relacionados con la ausencia de respeto hacia el mundo de la infancia, y en muchos otros casos en relación con el escaso respeto a la dignidad de las mujeres, por poner dos ejemplos frecuentes en este sentido.

\section{Los instrumentos para el control: Sanciones, recomendaciones, decisiones, instrucciones}

Las competencias de los organismos reguladores no tendrían validez si no fuera por la capacidad sancionadora que los distingue. Con frecuencia, personas poco entendidas, o incluso desde determinados medios de comunicación, han calificado esta labor como "censura". No cabe duda de que una de las funciones de los consejos audiovisuales es la de impedir que determinados contenidos ilegales o perjudiciales se emitan $\mathrm{o}$, más frecuentemente, continúen emitiéndose por televisión.

Pero esa no es, en absoluto, la labor más importante que le corresponde a estos organismos. Más bien al contrario, su labor debe articularse en torno a garantizar la pluralidad, la libertad, la independencia y la defensa de 
los derechos de la audiencia frente a los frecuentes abusos que desde determinados operadores se llevan a cabo.

Es por eso que estos organismos se han ido dotando de una serie de elementos que le permitan hacer parte de esta labor. Dependiendo de cuáles sean las características de la situación ante la que se enfrentan, los consejos audiovisuales pueden optar por una gama de soluciones que se adapten a la necesidad que se ha creado y que respondan satisfactoriamente a esta.

De esa forma, las posibilidades de actuación contemplan una variedad de opciones, entre las que caben destacar las siguientes: instrucciones (en los casos en que se trata de obligar en forma general a que los operadores o anunciantes cumplan unas determinadas normas o códigos), decisiones (cuando esa misma orden tiene un ámbito de cumplimiento mucho más reducido y que por lo general se dirige a individuos o entidades concretas y no a todo el espectro audiovisual), recomendaciones (que al contrario que en los dos casos anteriores no tienen un carácter vinculante sino solo orientativo), sanciones (cuando los mecanismos anteriores fallan y se necesita tomar una resolución más drástica, o cuando directamente, debido a la gravedad de la falta cometida, se decide penalizar a un determinado operador o anunciante ante una violación importante de las leyes o de la normativa).
En su gran mayoría las sanciones suelen tener un carácter económico, e incluso, en casos particularmente graves, se puede llegar a la propuesta de cierre de un determinado operador, pero esta decisión corresponde a los tribunales, ya que escapa a las competencias que habitualmente los órganos de control tienen asumidas.

Por regla general, la labor de los consejos audiovisuales en este sentido suele ser bastante prudente, y las sanciones -como las propuestas de cierre- son casos extremos que generalmente no se aplican con frecuencia, entre otras cuestiones por la gran carga mediática que tienen, pero en especial porque implican soluciones extremas a problemas de gran envergadura. Lo habitual es establecer lo que se denomina una labor de mediación para conseguir -en forma voluntaria o mediante acuerdo- que el operador cese la emisión de determinados tipos de imágenes o de contenidos para evitar tener que recurrir a situaciones tan drásticas.

\section{Otras competencias de los consejos audiovisuales}

Frecuentemente, las palabras regulación y consejo son utilizadas indistintamente, casi como si fueran sinónimos, a la hora de describir la labor que se lleva a cabo en estos organismos o instituciones. Ambos términos reflejan en buena medida el objetivo que deben cumplir: el control de los 
contenidos y también el foro de reflexión en el que se debaten los problemas y las posibles respuestas a las infracciones o abusos en los contenidos radiotelevisivos.

Pero hay diferencias entre una y otra entidad, aunque en ambas las dos palabras responden a las labores básicas que en ellas se realizan.

Hasta ahora hemos venido analizando principalmente la que sería la primera labor: la de control, ya que esta es, sin duda, la más significativa y conocida, pero hay también otras muy importantes y más amplias que entrarían más en la segunda acepción, la de aconsejar, más que en la primera, la de controlar.

A continuación nos ocuparemos del segundo caso, centrándonos en lo que sería el apartado de los contenidos audiovisuales, objeto de nuestro estudio.

La investigación es una de las tareas complementarias que se realizan en los consejos. Esta labor resulta básica para preparar la documentación, la búsqueda de datos, la realización de determinados estudios, etcétera, que complementen la actividad, hasta cierto punto "mecánica" que se realiza para el control de los contenidos.

La organización de encuentros, jornadas, foros, congresos o cualquier tipo de reunión en la que se debata sobre aspectos relacionados con la cuestión que nos ocupa es otra de las tareas importantes que han de desa- rrollarse, para poner en contacto a especialistas y técnicos de diferentes ámgbitos que trabajan sobre estas cuestiones.

En este mismo sentido también destacan las publicaciones. Los consejos fomentan la edición de tesis doctorales, de libros de gran interés en relación con su temática que estén agotados, patrocinan premios de investigación con el objeto de publicar las obras para su difusión, fundan revistas para divulgar sus actuaciones, etcétera.

La catalogación o archivo de toda la información que generan están también entre las labores que sirven de apoyo al control y análisis de contenidos. Videotecas, hemerotecas, bibliotecas, mediatecas son espacios en los que se almacenan, en forma catalogada, toda la información audiovisual, escrita o en cualquier otro formato, que permita tanto su conservación como que facilite el hecho de pueda ser utilizado en posteriores estudios.

Citemos, finalmente, la labor pedagógica y divulgativa, tantas veces olvidada e incluso muchas veces denostada en forma injusta. La denominada media literacy, traducida libremente al castellano como "alfabetización mediática" es una de las tareas que la mayor parte de los consejos europeos e incluso mundiales se han propuesto conseguir como objetivo básico de sus competencias. Educar a la audiencia para conseguir que se 
haga un consumo crítico y activo de los medios es una de las actividades más importantes en la que están empeñadas numerosas autoridades reguladoras, en colaboración la mayoría de las veces con otras instituciones políticas y sociales a las que también compete esta temática (autoridades educativas, sociales, asociaciones de telespectadores). Tarea que, sin embargo, en España, parece todavía estar bastante lejos de ser una labor primordial de los consejos existentes.

\section{Conclusiones}

A lo largo de este artículo hemos venido insistiendo en una idea que es básica para comprender qué es un consejo audiovisual o qué sentido tiene el control de los contenidos audiovisuales por parte de las autoridades reguladoras. La regulación de los contenidos que se emiten no está en contradicción con la verdadera labor de los consejos u organismos de regulación, la de ser garantes de derechos y libertades de la ciudadanía en general y de la audiencia en particular. Las sociedades libres e independientes necesitan de su existencia como vía tanto de canalización de sus demandas contra los abusos en los medios, como de elementos de protección ante los colectivos más desprotegidos que albergan en su seno. Queda aún una labor muy importante por realizar, la de la concienciación de las personas ante el consumo indiscriminado de los medios y la necesidad de "educar" a las audiencias y a los telespectadores para que su se haga desde una perspectiva madura y crítica, como se demanda cada vez más desde numerosos colectivos sociales.

\section{Bibliografía}

ARNANZ, C. M.; CASTILLEJO, G. y B. GONZÁLEZ (coords.). ¿Queréis un buen consejo? El sector ante el Consejo Audiovisual. Madrid: Academia de las Ciencias y las Artes de Televisión, 2004.

AZNAR, H. Comunicación responsable. Deontología y autorregulación de los medios. Barcelona: Ariel \& Consell de 1'Audiovisual de Catalunya, 1999.

BUSTAMANTE, E. (ed.). Comunicación y cultura en la era digital. Industrias, mercados y diversidad en España. Barcelona: Gedisa, 2002.

CAMPS, V. "El lugar de la ética en los medios de comunicación", en VARIOS AUTORES. Éticas de la información y deontologías del periodismo. Madrid: Tecnos, 1995.

CASANOVA, G. y J. M. CASADO (eds.). El servicio público de la televisión. Granada: Universidad de Granada, 2005.

Comisión del Mercado de las Telecomunicaciones (CMT). Organismos reguladores independientes del sector audiovisual europeo. Madrid, 1999. 
CONSEJO DE EUROPA. Recomendación del Consejo de Europa a los Estados miembros sobre la independencia y las funciones de las autoridades reguladoras para el sector de la difusión. Recomendación REC (2000) 23, adoptada por el Comité de Ministros el 20 de diciembre de 2000 en la 735..$^{\text {a }}$ reunión de los Diputados de los Ministros, 2000.

GARCÍA CASTILLEJO, A. “La nueva sociedad de la información: El marco normativo de los medios audiovisuales", en VARIOS ATO-
RES. La nueva era de la televisión. Madrid: Corporación Multimedia \& ATV, 2001.

GARCÍA MATILLA, A. Una televisión para la educación. Barcelona: Gedisa, 2003.

JIMÉNEZ DE PARGA, M. La información en la era de la televización de los públicos. Barcelona: Consell de 1'Audiovisual de Catalunya, 1997.

TORNOS, J. Las autoridades de regulación de lo audiovisual. Madrid: Marcial Pons, 1999. 